\title{
Frailty in Patients with Cardiovascular Disease: Why, When, and How to Measure
}

\author{
Jonathan Afilalo
}

Published online: 2 August 2011

(C) The Author(s) 2011. This article is published with open access at Springerlink.com

\begin{abstract}
Frailty is a geriatric syndrome of impaired resistance to stressors due to a decline in physiologic reserve. Frailty and cardiovascular disease (CVD) share a common biological pathway, and CVD may accelerate the development of frailty. Frailty is identified in $25 \%$ to $50 \%$ of patients with CVD, depending on the frailty scale used and the population studied. Frail patients with CVD, especially those undergoing invasive procedures or suffering from coronary artery disease and heart failure, are more likely to suffer adverse outcomes as compared to their non-frail counterparts. Five-meter gait speed is a simple and effective way of objectively measuring frailty in patients with CVD and should be incorporated in risk assessment.
\end{abstract}

Keywords Aging · Frailty Cardiovascular diseases . Cardiac surgery

\section{Introduction}

The word frail originates from the French frêle, meaning "of little resistance," and from the Latin fragilis, meaning "easily broken." In medicine, frailty is a geriatric syndrome used to define older adults with impaired resistance to stressors due to a decline in physiologic reserve [1]. The decline in physiologic reserve is multifactorial and involves a number of organ systems. Implicit in this definition is the introduction of a stressor (illness,

\section{J. Afilalo $(\triangle)$}

Divisions of Cardiology and Clinical Epidemiology, Department of Medicine, SMBD-Jewish General Hospital, McGill University, 3755 Cote Ste Catherine,

Montreal, Quebec H3T 1E2, Canada

e-mail: jonathan@afilalo.com surgery) followed by an injury and/or incomplete recovery, and ultimately a greater risk of mortality and morbidity.

Frailty has become increasingly relevant in the field of cardiovascular medicine for two principal reasons. First, the patient population is aging; of the 6,160,000 Americans discharged with a first diagnosis of cardiovascular disease (CVD), $62 \%$ were $\geq 65$ years of age, and of those not surviving, $67 \%$ were $\geq 75$ years or age [2]. Chronologic age alone is insufficient to characterize the heterogeneous group of older adult patients, and consideration of frailty is important to better reflect biological age. Second, there is an emerging body of literature linking CVD and frailty both at the mechanistic level and the epidemiologic level [3].

The objectives of this review are to recapitulate the mechanistic and epidemiologic links between CVD and frailty and to provide a framework for when and how to measure frailty in CVD patients based on current evidence.

\section{Mechanistic Link Between CVD and Frailty}

Although the pathways leading to CVD and frailty are complex, both have been strongly tied to chronic low-grade inflammation (Fig. 1). Causes of this type of inflammation include lifelong antigenic exposure, angiotensin 1R activation, obesity, insulin resistance, and redox imbalance [4], all of which are found in greater relative amounts in patients with CVD and patients with frailty. Circulating inflammatory markers such as neutrophils, monocytes, highsensitivity C-reactive protein, and interleukin-6 (IL-6) are increased in CVD and frailty [5-7], as are downstream thrombotic markers such as factor VIII and D-Dimers [8]. 


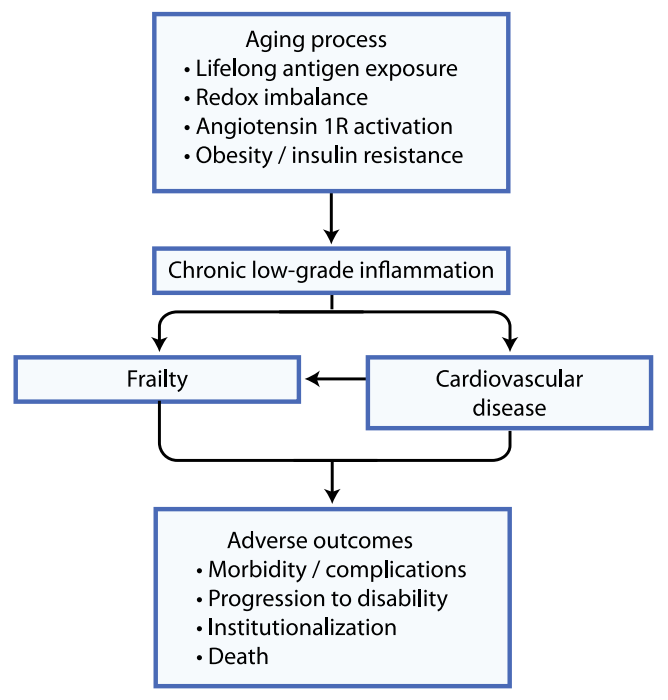

Fig. 1 Mechanistic link between frailty and cardiovascular disease

In CVD, inflammation plays a central role in oxidation of lipoproteins and activation of plaques [9]. In frailty, inflammation promotes a catabolic neurohormonal state that serves to redistribute amino acids from skeletal muscle to other organ systems, leading to profound loss of muscle mass $[10,11]$. Because muscle is the main reservoir for amino acids, loss of muscle mass and change in muscle metabolism impairs the body's ability to maintain and repair itself in the face of stressors $[12,13]$. Hence, loss of muscle mass is a core component of frailty.

Another common pathway leading to CVD and frailty is insulin resistance [14, 15]. Independent of its contribution to chronic inflammation, insulin resistance leads to impaired muscle protein breakdown, which in turn leads to reduced availability of amino acids for maintenance and repair functions. Vitamin D deficiency has also been implicated in both CVD and frailty [16-19], as well as a number of nuclear factors including telomere shortening [20-23] and lamin A/C reduction [24].

In addition to sharing causal pathways, CVD has been shown to contribute to the development of frailty $[25,26]$. The mechanism remains to be elucidated, but may be related to chronic repetitive injury and neurohormonal activation imposed by the CVD (eg, ischemic heart disease, hypertension, valvular heart disease).

\section{Epidemiologic Link Between CVD and Frailty}

Four studies suggested a cross-sectional association between prevalent frailty and prevalent CVD in communitydwelling older adults: Zutphen Elderly Men's Study (odds ratio [OR] 4.1; 95\% CI, 1.8-9.3; $n=450$ ) [27], Cardiovascular Health Study (OR 2.79; 95\% CI, 2.12-3.67; $n=4,735$ ) [28], Beaver Dam Eye Study (OR 1.43 per point; 95\% CI,
$1.13-1.82 ; n=2962)$ [29], and the Women's Health and Aging Studies (OR 2.72; 95\% CI, 1.72-4.30; $n=670$ ) [30]. In the Cardiovascular Health Study, there was also an association between frailty and subclinical cardiovascular abnormalities such as left ventricular hypertrophy and carotid intima-media thickness.

The Women's Health Initiative Observational Study showed that community-dwelling older women with CVD and cardiovascular risk factors were at higher risk of developing incident frailty [31]. Coronary artery disease and stroke were associated with the highest risk of developing incident frailty (OR 1.47; 95\% CI, 1.25-1.73 and OR 1.71; 95\% CI, 1.24-2.36, respectively; $n=40,657$ ). In this study and others, frailty was strongly predictive of survival over a long-term follow-up period.

The French 3 City Study and the Health ABC Study showed that community-dwelling older adults who were frail (as determined by gait speed) were at higher risk of developing incident CVD events and mortality $[25,26]$. In the French 3 City Study, slow gait speed was associated with a threefold increase in cardiovascular mortality over 5 years (OR $3.00 ; 95 \%$ CI, $1.65-5.57 ; n=3208$ ) but no difference in death due to cancer or death due to other causes, implying a specific effect of frailty on CVD.

Outside of the community setting, there have been fewer studies examining the prevalence and prognostic impact of frailty in hospitalized older adults or those with established severe CVD. Purser et al. [32•] showed that, depending on the definition used, $27 \%$ to $50 \%$ of elderly patients admitted to a cardiology ward with severe coronary artery disease were frail [32•]. Slow gait speed outperformed other markers of frailty and was associated with a fourfold increase in mortality over 6 months (OR 4.00; 95\% CI, 1.10-13.80; $n=309$ ). Cacciatore et al. [33] showed that $54 \%$ of elderly patients with chronic heart failure were frail, which was in turn associated with an increase in mortality over 12 years (OR 1.62; 95\% CI, 1.08$2.45 ; n=1332$ ) [33]. Using a different definition of frailty, Boxer et al. [34] showed that $25 \%$ of elderly patients with chronic heart failure were frail. Tjam et al. [35] showed that frailty was more predictive of mortality than New York Heart Association (NYHA) class.

The sum of these epidemiologic studies underscores the frequent coexistence of frailty and CVD, with the prevalence of frailty varying between $25 \%$ and $50 \%$ depending on the definition used. Furthermore, these studies brought forth the non-negligible impact of frailty on CVD events and mortality.

\section{When to Measure Frailty}

Because frailty is a syndrome of impaired resistance to stressors, it is well suited to predict the elderly patient's 
response to cardiovascular stress. One of the most promising clinical applications lies in using frailty to predict the elderly patient's risk of mortality and morbidity in the setting of invasive cardiovascular procedures. In particular, cardiac surgery imposes marked physiologic stress on numerous organ systems, and existing risk prediction models perform poorly in the elderly [36]. These models contain up to 77 variables encompassing patient age, sex, illness severity, and comorbid conditions, but they have yet to formally incorporate an objective measure of frailty.

In the Frailty Assessment Before Cardiac Surgery (Frailty ABC'S) Study, $46 \%$ of elderly patients aged 70 years or older undergoing coronary artery bypass surgery and/or valve surgery were found to be frail as measured by a $5-\mathrm{m}$ gait speed $\geq 6 \mathrm{~s}[37 \bullet]$. Gait speed was not correlated with age, left ventricular ejection fraction, or risk scores, suggesting that it was representing a distinct domain. After adjusting for the Society of Thoracic Surgeons (STS) risk score, slow gait speed was associated with a threefold increase in postoperative mortality or major morbidity (OR 3.05; 95\% CI, 1.23-7.54; $n=131$ ). Slow gait speed was also associated with greater need for discharge to convalescence or rehabilitation facilities, and a trend toward a longer length of stay. The value of adding gait speed to the STS risk score was incremental and resulted in a substantial improvement in area under the receiver operating characteristic (ROC) curve from 0.70 to 0.74 and integrated discrimination index of $5 \%$, two measures of model performance.

In a study from the Maritime Heart Center Cardiac Surgery Registry, only $4 \%$ of patients undergoing cardiac surgery were found to be frail; having increased mortality and discharge to convalescence or rehabilitation facilities [38]. The low prevalence of frailty could be explained by the mixture of elderly and non-elderly patients, and the definition of frailty that was based on disability ("endstage" frailty) and dementia rather than conventional criteria for frailty. This study underscores the relatively lower yield of frailty in non-elderly patients and when disability-based criteria are used.

A study from the Heart Center Leipzig included patients aged $\geq 74$ years undergoing cardiac surgery [39]. The definition of frailty was based on a composite score (range of 1-35) using a modified Cardiovascular Health Study scale, instrumental activities of daily living, balance testing, a panel of laboratory tests, and pulmonary function tests. The unadjusted risk of postoperative mortality was greater in those with higher composite scores.

Another promising clinical application for frailty lies in predicting the elderly patient's risk of mortality and morbidity in the setting of heart failure [33-35]. These patients often have very advanced age, many comorbid conditions, frequent hospitalizations, and high mortality rates, rendering the clinical evaluation and management decisions complex. Frailty may enlighten the global assessment and at times explain nonspecific symptoms such as exhaustion and weakness.

Finally, frailty may be measured in any elderly patient with CVD when a global assessment is desired to better reflect complexities related to advanced age, comorbidity, disability, and nonspecific symptomatology.

\section{How to Measure Frailty}

A number of different clinical instruments exist to objectively measure the phenotype of frailty $[40 \bullet, 41]$. These instruments vary from 1 to 70 items, but tend to share similar core items: slowness, weakness, and physical inactivity.

One of the most widely used instruments is the Cardiovascular Health Study (CHS) scale [42•]. The CHS scale includes 5 items: slowness measured by $5-\mathrm{m}$ gait speed, weakness measured by handgrip strength, physical inactivity measured by questionnaire, exhaustion measured by questionnaire, and unintentional weight loss $>10 \mathrm{lbs}$ over 1 year measured by self-report. Three or more positive items are required to classify the patient as frail, and one or two positive items are required to classify the patient as pre-frail. The pre-frail category is disregarded by some because its prognostic utility is less well established.

There have been a number of modifications to the CHS scale. The expanded CHS scale adds two items to the standard CHS scale-cognitive impairment and mood disturbance - because some believe these to be integral components of frailty. The MacArthur Study of Successful Aging (MSSA) scale adds five items: cognitive impairment, self-reported weakness, anorexia, high IL-6, and high CRP; four or more positive items are required to classify the patient as frail [43•]. An analysis of the MSSA scale subdimensions revealed that the combination of slowness, weakness, physical inactivity, and cognitive impairment was most predictive.

Of note, many investigators have found that the single item of slow gait speed is most predictive of frailty and adverse outcomes, often outperforming more elaborate scales and other physical performance tests such as handgrip strength, chair-rises, and balance testing [32•, 44, 45]. The single measure of gait speed for frailty has been endorsed by a recent task force [40॰], and has the advantage of being easily applicable without much time or cost and without relying on subjective questionnaires. Gait speed is typically measured over a 5-m distance (range of 2.4-10 m, with the distance used having little effect on measured speed) [46] at the patient's comfortable walking pace. 
Instructions for performing the 5-m gait speed test can be found in Fig. 2.

Jones et al. [47] have proposed two additional frailty scales. The Canadian Health and Aging (CHSA) Frailty Index includes a checklist of 70 items, integrating a large number of comorbid conditions, disabilities, cognitive impairments, mood disturbances, and mobility limitations. The CHSA Clinical Frailty Scale simplifies this checklist into a semi-quantitative global judgment that classifies patients on a scale from 1 to 7 with 1 being very fit and 7 being severely frail [48].

The Calgary Cardiac and Cognition scale was developed in hospitalized patients aged $\geq 60$ years undergoing cardiac catheterization, with the stated goal of predicting worsening activities of daily living (ADL) and quality of life over a period of 1 year [49]. Like the CHS scale, the Calgary Cardiac and Cognition scale includes five items with three or more required to classify a patient as frail: cognitive impairment measured by the Trail-Making Test Part B, mood disturbance measured by the geriatric depression scale, tandem balance $<10 \mathrm{~s}$, body mass index $<21$ or $>30 \mathrm{~kg} / \mathrm{m}^{2}$, and living alone. Gait speed was not predictive in this study, although a short 2.4-m test was used and the investigators pointed out that many patients were restrained by intravenous lines. Conversely, in the Frailty ABC'S Study, the presence of intravenous lines, walkers, and canes did not affect the reliability of the gait speed test.

One common pitfall is equating frailty with disabilities in ADL (e.g., getting dressed unassisted) or instrumental ADL (e.g., going shopping unassisted). Frailty occurs earlier and can be elicited in a large number of wellfunctioning older adults; disability occurs later and can be viewed as the end-result of longstanding frailty and comorbidity burden. Despite the overlap between frailty, disability, and comorbid conditions, these represent distinct domains that are not interchangeable [50]. Another common pitfall is identifying frailty based on a visual "eyeball" impression, especially when this visual impression is driven by the presence of very advanced age and low body mass index. In fact, frail patients are more likely to have high body mass index and excess central adiposity [14, 37•, 51].

\section{Future Directions}

With the emergence of evidence showing the prognostic value of frailty in elderly patients with CVD, ongoing efforts are being directed toward incorporating frailty into existing and novel risk prediction models. Until these models are available, clinicians may consider measuring frailty in selected patients on a case-by-case basis.

Therapeutic strategies may be divided as those that prevent or reverse the development of frailty, and those that prevent adverse outcomes in frail patients. Interventions likely to be beneficial in preventing frailty include regular physical exercise [52-58] and balanced nutrition. The value of pharmacotherapy remains to be confirmed. Interventions likely to prevent adverse outcomes in patients found to be frail include comprehensive geriatric assessment to optimize comorbid conditions and promote early recognition of complications such as delirium [59-61], physical therapy $[62,63]$, and accessibility to social support systems [64, 65]. Moreover, frail patients requiring coronary revascularization or valve replacement may benefit from less invasive
Fig. 2 Instructions for the 5-m gait speed test

\begin{tabular}{|c|c|}
\hline \multirow[t]{7}{*}{$\begin{array}{l}\text { 5-meter gait } \\
\text { speed test }\end{array}$} & $\begin{array}{l}\text { In an unobstructed area, position the patient with his/her feet } \\
\text { behind and just touching the } 0 \text {-meter start line }\end{array}$ \\
\hline & $\begin{array}{l}\text { Instruct to "Walk at your comfortable pace" until a few steps past } \\
\text { the 5-meter mark (should not start to slow down before) }\end{array}$ \\
\hline & Begin each trial on the word "Go" \\
\hline & Start the timer with the first footfall after the 0 -meter line \\
\hline & Stop the timer with the first footfall after the 5 -meter line \\
\hline & $\begin{array}{l}\text { Repeat } 3 \text { times and record average, allowing sufficient time for } \\
\text { recuperation between trials }\end{array}$ \\
\hline & $\begin{array}{l}\text { Frailty is defined as an average time taken to walk the } 5 \text {-meter } \\
\text { course } \geq 6 \text { seconds* }\end{array}$ \\
\hline
\end{tabular}


therapeutic options, such as minimally invasive surgery or transcatheter interventions, although this has yet to be formally studied.

\section{Conclusions}

Frailty and CVD share common biological pathways, and CVD may accelerate the development of frailty. Frailty is identified in $25 \%$ to $50 \%$ of patients with CVD, depending on the frailty scale used and the population studied. Frail patients with CVD, especially those undergoing invasive procedures or suffering from coronary artery disease and heart failure, are more likely to suffer adverse outcomes compared to their non-frail counterparts. The 5-m gait speed test is a simple and effective way of objectively measuring frailty in patients with CVD and should be incorporated in risk assessment. Further research will clarify how to best incorporate frailty in existing risk models and how to optimize health status and prevent adverse outcomes in frail patients.

Disclosure No conflicts of interest relevant to this article were reported.

Open Access This article is distributed under the terms of the Creative Commons Attribution Noncommercial License which permits any noncommercial use, distribution, and reproduction in any medium, provided the original author(s) and source are credited.

\section{References}

Papers of particular interest, published recently, have been highlighted as:

\section{- Of importance}

1. Bergman H, Ferrucci L, Guralnik J, et al. Frailty: an emerging research and clinical paradigm-issues and controversies. J Gerontol A Biol Sci Med Sci. 2007;62:731-7.

2. 2010 Statistical Fact Sheet: Older Americans and Cardiovascular Diseases. American Heart Association. (Accessed April 6 2011, at http://www.americanheart.org/downloadable/heart/126081187 7868FS08OLD10.pdf).

3. Afilalo J, Karunananthan S, Eisenberg MJ, Alexander KP, Bergman H. Role of frailty in patients with cardiovascular disease. Am J Cardiol. 2009;103:1616-21.

4. De Martinis M, Franceschi C, Monti D, Ginaldi L. Inflammation markers predicting frailty and mortality in the elderly. Exp Mol Pathol. 2006;80:219-27.

5. Visser M, Pahor M, Taaffe DR, et al. Relationship of interleukin-6 and tumor necrosis factor-alpha with muscle mass and muscle strength in elderly men and women: the Health ABC Study. J Gerontol A Biol Sci Med Sci. 2002;57:M326-32.

6. Cesari M, Penninx BWJH, Pahor M, et al. Inflammatory markers and physical performance in older persons: the InCHIANTI study. J Gerontol A Biol Sci Med Sci. 2004;59:242-8.
7. Leng SX, Xue Q-L, Tian J, Huang Y, Yeh S-H, Fried LP. Associations of neutrophil and monocyte counts with frailty in community-dwelling disabled older women: results from the Women's Health and Aging Studies I. Exp Gerontol. 2009;44:511-6.

8. Walston J, McBurnie MA, Newman A, et al. Frailty and activation of the inflammation and coagulation systems with and without clinical comorbidities: results from the Cardiovascular Health Study. Arch Intern Med. 2002;162:2333-41.

9. Hansson GK. Inflammation, atherosclerosis, and coronary artery disease. N Engl J Med. 2005;352:1685-95.

10. Chevalier S, Gougeon R, Nayar K, Morais JA. Frailty amplifies the effects of aging on protein metabolism: role of protein intake. Am J Clin Nutr. 2003;78:422-9.

11. Wolfe RR. Optimal nutrition, exercise, and hormonal therapy promote muscle anabolism in the elderly. J Am Coll Surg. 2006;202:176-80.

12. Morais JA, Ross R, Gougeon R, Pencharz PB, Jones PJ, Marliss EB. Distribution of protein turnover changes with age in humans as assessed by whole-body magnetic resonance image analysis to quantify tissue volumes. J Nutr. 2000;130:784-91.

13. Wu G. Amino acids: metabolism, functions, and nutrition. Amino Acids. 2009;37:1-17.

14. Barzilay JI, Blaum C, Moore T, et al. Insulin resistance and inflammation as precursors of frailty: the Cardiovascular Health Study. Arch Intern Med. 2007;167:635-41.

15. Goulet EDB, Hassaine A, Dionne IJ, et al. Frailty in the elderly is associated with insulin resistance of glucose metabolism in the postabsorptive state only in the presence of increased abdominal fat. Exp Gerontol. 2009;44:740-4.

16. Reddy Vanga S, Good M, Howard PA, Vacek JL. Role of vitamin D in cardiovascular health. Am J Cardiol. 2010;106:798-805.

17. Ensrud KE, Blackwell TL, Cauley JA, et al. Circulating 25hydroxyvitamin D levels and frailty in older men: the osteoporotic fractures in men study. J Am Geriatr Soc. 2011;59:101-6.

18. Rosen CJ, Manson JE. Frailty: a D-ficiency syndrome of aging? J Clin Endocrinol Metab. 2010;95:5210-2.

19. Shardell M, Hicks GE, Miller RR, et al. Association of low vitamin D levels with the frailty syndrome in men and women. J Gerontol A Biol Sci Med Sci. 2009;64:69-75.

20. Blasco MA. Telomere length, stem cells and aging. Nat Chem Biol. 2007;3:640-9.

21. Brouilette SW, Moore JS, McMahon AD, et al. Telomere length, risk of coronary heart disease, and statin treatment in the West of Scotland Primary Prevention Study: a nested case-control study. Lancet. 2007;369:107-14.

22. van der Harst P, van der Steege G, de Boer RA, et al. Telomere length of circulating leukocytes is decreased in patients with chronic heart failure. J Am Coll Cardiol. 2007;49:1459-64.

23. Woo J, Tang NLS, Suen E, Leung JCS, Leung PC. Telomeres and frailty. Mech Ageing Dev. 2008;129:642-8.

24. Afilalo J, Sebag IA, Chalifour LE, et al. Age-related changes in lamin $\mathrm{A} / \mathrm{C}$ expression in cardiomyocytes. Am J Physiol Heart Circ Physiol. 2007;293:H1451-6.

25. Dumurgier J, Elbaz A, Ducimetière P, Tavernier B, Alpérovitch A, Tzourio C. Slow walking speed and cardiovascular death in well functioning older adults: prospective cohort study. BMJ. 2009;339:b4460.

26. Newman AB, Simonsick EM, Naydeck BL, et al. Association of longdistance corridor walk performance with mortality, cardiovascular disease, mobility limitation, and disability. JAMA. 2006;295:2018-26.

27. Chin A, Paw MJ, Dekker JM, Feskens EJ, Schouten EG, Kromhout D. How to select a frail elderly population? A comparison of three working definitions. J Clin Epidemiol. 1999;52:1015-21.

28. Newman AB, Gottdiener JS, Mcburnie MA, et al. Associations of subclinical cardiovascular disease with frailty. J Gerontol A Biol Sci Med Sci. 2001;56:M158-66. 
29. Klein BEK, Klein R, Knudtson MD, Lee KE. Frailty, morbidity and survival. Arch Gerontol Geriatr. 2005;41:141-9.

30. Chaves PHM, Semba RD, Leng SX, et al. Impact of anemia and cardiovascular disease on frailty status of community-dwelling older women: the Women's Health and Aging Studies I and II. J Gerontol A Biol Sci Med Sci. 2005;60:729-35.

31. Woods NF, Lacroix AZ, Gray SL, et al. Frailty: emergence and consequences in women aged 65 and older in the Women's Health Initiative Observational Study. J Am Geriatr Soc. 2005;53:132130.

32. - Purser JL, Kuchibhatla MN, Fillenbaum GG, Harding T, Peterson ED, Alexander KP. Identifying frailty in hospitalized older adults with significant coronary artery disease. J Am Geriatr Soc. 2006;54:1674-81. This is one of the first studies to prospectively measure frailty in patients with severe CVD.

33. Cacciatore F, Abete P, Mazzella F, et al. Frailty predicts long-term mortality in elderly subjects with chronic heart failure. Eur J Clin Invest. 2005;35:723-30.

34. Boxer RS, Dauser DA, Walsh SJ, Hager WD, Kenny AM. The association between vitamin $\mathrm{D}$ and inflammation with the 6minute walk and frailty in patients with heart failure. J Am Geriatr Soc. 2008;56:454-61.

35. Tjam EY, Heckman GA, Smith S, et al. Predicting heart failure mortality in frail seniors: Comparing the NYHA functional classification with the Resident Assessment Instrument (RAI) 2.0. Int J Cardiol. 2011.

36. Dupuis J-Y. Predicting outcomes in cardiac surgery: risk stratification matters? Curr Opin Cardiol. 2008;23:560-7.

37. - Afilalo J, Eisenberg MJ, Morin J-F, et al. Gait speed as an incremental predictor of mortality and major morbidity in elderly patients undergoing cardiac surgery. J Am Coll Cardiol. 2010;56:1668-76. This is a prospective multicenter study of frailty in patients undergoing cardiac surgery.

38. Lee DH, Buth KJ, Martin B-J, Yip AM, Hirsch GM. Frail patients are at increased risk for mortality and prolonged institutional care after cardiac surgery. Circulation. 2010;121:973-8.

39. Sündermann S, Dademasch A, Praetorius J, et al. Comprehensive assessment of frailty for elderly high-risk patients undergoing cardiac surgery. Eur J Cardiothorac Surg. 2011;39:33-7.

40. - Abellan van Kan G, Rolland Y, Bergman H, Morley JE, Kritchevsky SB, Vellas B. The I.A.N.A Task Force on frailty assessment of older people in clinical practice. J Nutr Health Aging 2008;12:29-37. This is a comprehensive review of the literature on frailty, with recommendations for use.

41. de Vries NM, Staal JB, van Ravensberg CD, Hobbelen JSM. Olde Rikkert MGM, Nijhuis-van der Sanden MWG. Outcome instruments to measure frailty: a systematic review. Ageing Res Rev. 2011;10:104-14.

42. - Fried LP, Tangen CM, Walston J, et al. Frailty in older adults: evidence for a phenotype. J Gerontol A Biol Sci Med Sci. 2001;56:M146-56. This is a seminal paper on frailty that put forth the CHS frailty scale.

43. - Sarkisian CA, Gruenewald TL, John Boscardin W, Seeman TE. Preliminary evidence for subdimensions of geriatric frailty: the MacArthur study of successful aging. J Am Geriatr Soc. 2008;56:2292-7. In this article, the modifications and subdimensions of the CHS scale are explored.

44. Studenski S, Perera S, Wallace D, et al. Physical performance measures in the clinical setting. J Am Geriatr Soc. 2003;51:31422

45. Afilalo J, Mottillo S, Alexander KP, et al. Identification of vulnerable elderly before cardiac surgery: a comparison of different survey scales. J Am Coll Cardiol. 2011;57:E1395.

46. Graham JE, Ostir GV, Kuo Y-F, Fisher SR, Ottenbacher KJ. Relationship between test methodology and mean velocity in timed walk tests: a review. Arch Phys Med Rehabil. 2008;89:865-72.
47. Jones DM, Song X, Rockwood K. Operationalizing a frailty index from a standardized comprehensive geriatric assessment. J Am Geriatr Soc. 2004;52:1929-33.

48. Rockwood K, Song X, MacKnight C, et al. A global clinical measure of fitness and frailty in elderly people. Can Med Assoc J. 2005;173:489-95.

49. Freiheit EA, Hogan DB, Eliasziw M, et al. Development of a frailty index for patients with coronary artery disease. J Am Geriatr Soc. 2010;58:1526-31.

50. Fried LP, Ferrucci L, Darer J, Williamson JD, Anderson G. Untangling the concepts of disability, frailty, and comorbidity: implications for improved targeting and care. J Gerontol A Biol Sci Med Sci. 2004;59:255-63.

51. Gallagher D, Ruts E, Visser M, et al. Weight stability masks sarcopenia in elderly men and women. Am J Physiol Endocrinol Metab. 2000;279:E366-75.

52. Latham NK, Bennett DA, Stretton CM, Anderson CS. Systematic review of progressive resistance strength training in older adults. J Gerontol A Biol Sci Med Sci. 2004;59:48-61.

53. Liu CK, Fielding RA. Exercise as an intervention for frailty. Clin Geriatr Med. 2011;27:101-10.

54. Williams MA, Maresh CM, Esterbrooks DJ, Harbrecht JJ, Sketch MH. Early exercise training in patients older than age 65 years compared with that in younger patients after acute myocardial infarction or coronary artery bypass grafting. Am J Cardiol. 1985;55:263-6.

55. Witham MD, Gray JM, Argo IS, Johnston DW, Struthers AD, McMurdo MET. Effect of a seated exercise program to improve physical function and health status in frail patients $>$ or $=70$ years of age with heart failure. Am J Cardiol. 2005;95:1120-4.

56. Weening-Dijksterhuis E, de Greef MHG, Scherder EJA, Slaets JPJ, van der Schans CP. Frail institutionalized older persons: a comprehensive review on physical exercise, physical fitness, activities of daily living, and quality-of-life. Am J Phys Med Rehabil. 2011;90:156-68.

57. Peterson MJ, Giuliani C, Morey MC, et al. Physical activity as a preventative factor for frailty: the health, aging, and body composition study. J Gerontol A Biol Sci Med Sci. 2009;64:61-8.

58. Rydwik E, Frändin K, Akner G. Effects of a physical training and nutritional intervention program in frail elderly people regarding habitual physical activity level and activities of daily living-a randomized controlled pilot study. Arch Gerontol Geriatr. 2010;51:283-9.

59. Wells JL, Seabrook JA, Stolee P, Borrie MJ, Knoefel F. State of the art in geriatric rehabilitation. Part I: review of frailty and comprehensive geriatric assessment. Arch Phys Med Rehabil. 2003;84:890-7.

60. Bakker FC, Robben SHM, Olde Rikkert MGM. Effects of hospital-wide interventions to improve care for frail older inpatients: a systematic review. BMJ Qual Saf. 2011.

61. Li C-M, Chen C-Y, Li C-Y, Wang W-D, Wu S-C. The effectiveness of a comprehensive geriatric assessment intervention program for frailty in community-dwelling older people: a randomized, controlled trial. Arch Gerontol Geriatr. 2010;50 Suppl 1:S39-42.

62. Hoogeboom TJ, Dronkers JJ, van den Ende CHM, Oosting E, van Meeteren NLU. Preoperative therapeutic exercise in frail elderly scheduled for total hip replacement: a randomized pilot trial. Clin Rehabil. 2010;24:901-10.

63. Gill TM, Baker DI, Gottschalk M, Peduzzi PN, Allore H, Byers A. A program to prevent functional decline in physically frail, elderly persons who live at home. N Engl J Med. 2002;347:1068-74.

64. Allen KR, Hazelett SE, Jarjoura D, et al. The after discharge care management of low income frail elderly (AD-LIFE) randomized trial: Theoretical framework and study design $(*)$. Population Health Management 2011.

65. Gravelle H, Dusheiko M, Sheaff R, et al. Impact of case management (Evercare) on frail elderly patients: controlled before and after analysis of quantitative outcome data. BMJ. 2007;334:31. 